\title{
Paf receptor expression in the marsupial embryo and endometrium during embryonic diapause
}

\author{
Jane C Fenelon, Geoff Shaw, Chris $\mathrm{O}^{\prime} \mathrm{Neill}^{1}$, Stephen Frankenberg and Marilyn B Renfree \\ Department of Zoology, The University of Melbourne, Parkville, Victoria 3010, Australia and ${ }^{1}$ Sydney Medical School, \\ Kolling Institute for Medical Research, Centre for Developmental and Regenerative Medicine, University of Sydney, \\ Sydney, New South Wales 2065, Australia
}

Correspondence should be addressed to J C Fenelon who is now at Centre de Recherche en Reproduction Animale, Faculté de Médicine Vétérinaire, Université de Montréal, 3200 Rue Sicotte, CP 5000, Saint-Hyacinthe, Quebec, Canada J2S 7C6;

Email: j.fenelon@zoology.unimelb.edu.au

\begin{abstract}
The control of reactivation from embryonic diapause in the tammar wallaby (Macropus eugenii) involves sequential activation of the corpus luteum, secretion of progesterone that stimulates endometrial secretion and subsequent changes in the uterine environment that activate the embryo. However, the precise signals between the endometrium and the blastocyst are currently unknown. In eutherians, both the phospholipid Paf and its receptor, platelet-activating factor receptor (PTAFR), are present in the embryo and the endometrium. In the tammar, endometrial Paf release in vitro increases around the time of the early progesterone pulse that occurs around the time of reactivation, but whether Paf can reactivate the blastocyst is unknown. We cloned and characterised the expression of PTAFR in the tammar embryo and endometrium at entry into embryonic diapause, during its maintenance and after reactivation. Tammar PTAFR sequence and protein were highly conserved with mammalian orthologues. In the endometrium, PTAFR was expressed at a constant level in the glandular epithelium across all stages and in the luminal epithelium during both diapause and reactivation. Thus, the presence of the receptor appears not to be a limiting factor for Paf actions in the endometrium. However, the low levels of PTAFR in the embryo during diapause, together with its up-regulation and subsequent internalisation at reactivation, supports earlier results suggesting that endometrial Paf could be involved in reactivation of the tammar blastocyst from embryonic diapause.
\end{abstract}

Reproduction (2014) 147 21-31

\section{Introduction}

Embryonic diapause in mammals is a period of developmental arrest, in which the blastocyst is maintained in a dormant state for an extended period of time. Over 100 species of mammals undergo embryonic diapause (Renfree \& Calaby 1981, Renfree \& Shaw 2000), including the mouse and around 30 species of marsupials. In marsupials, the control of diapause is best understood in the tammar wallaby (Macropus eugenii) in which the blastocyst remains quiescent for 11 months. The marsupial blastocyst differs from that of eutherian mammals in that there is no inner cell mass at any stage. The blastocyst in diapause consists of a unilaminar layer of about 80 cells and there is no sign of an embryonic disc until around day 9 after removal of the pouch young (RPY; Renfree 1994, Frankenberg et al. 2013). In the tammar, the external and physiological mechanisms controlling entry into and reactivation from diapause have been well established (Tyndale-Biscoe \& Renfree 1987). Lactational or seasonal factors inhibit the development of the corpus luteum, keeping the secretion of progesterone low and the endometrium unstimulated
(Tyndale-Biscoe et al. 1974, Renfree et al. 1979). Removal of this inhibition of the corpus luteum leads to a pulse of progesterone between days 4 and 7 , but usually on day 5, after RPY to reactivate the diapausing blastocyst (Hinds \& Tyndale-Biscoe 1982, Hinds et al. 1983, Shaw \& Renfree 1984). This pulse of progesterone induces a secretory endometrium, which in turn reactivates the blastocyst (Renfree 1972, 1994, Renfree \& TyndaleBiscoe 1973). Subsequently, the first signs of reactivation are observed in the blastocyst, including a resumption of mitosis by day 4 RPY and a change in metabolism by day 5 RPY, with the first measurable expansion of the blastocyst occurring at day 8 RPY (Fig. 1; Thornber et al. 1981, Shaw \& Renfree 1986, Tyndale-Biscoe \& Renfree 1987, Shaw 1996, Spindler et al. 1998, 1999). However, how these proximal signals in the uterine environment are translated by the embryo to reactivate the diapausing blastocyst is unknown. One potential regulator is Paf (1-o-alkyl-2-acetyl-sn-glycero-3-phosphocholine).

Paf is a potent ether phospholipid that is involved in numerous aspects of pregnancy (Tiemann 2008). The binding of Paf to the platelet-activating factor receptor 


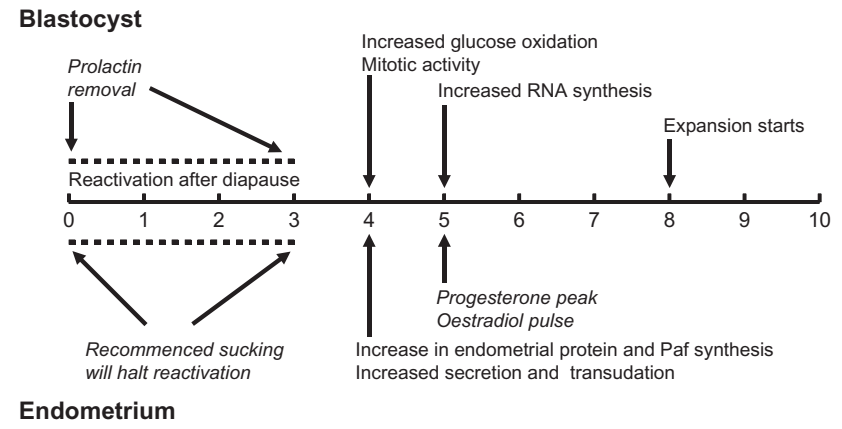

Figure 1 Summary of the timing of events during reactivation from diapause of the embryo and endometrium in the tammar wallaby after removal of the pouch young (RPY). The RPY-induced prolactin inhibition on day 0 initiates the events that reactivate the blastocyst from embryonic diapause. Thus, the timings of all subsequent reactivation stages are determined relative to this day of RPY, including the progesterone pulse, coinciding with an oestradiol- $17 \beta$ pulse, which reactivates the endometrium. Also around this time, the first signs of reactivation are observed in the blastocyst and the first increase in uterine Paf secretion occurs (Kojima et al. 1993) followed by the first measurable expansion of the blastocyst. Adapted from Shaw G 1996 The uterine environment in early pregnancy in the tammar wallaby. Reproduction, Fertility, and Development 8 811-818.

(PTAFR), a member of the $G$ protein-coupled receptor family, accounts for many of the reported actions of Paf (Ishii et al. 2002). Paf is produced and released by embryos during preimplantation development of all eutherian species studied to date: mouse $\left(\mathrm{O}^{\prime}\right.$ Neill 1985, Ryan et al. 1989, Ammit \& O'Neill 1991, Roudebush et al. 2002), rabbit (Minhas et al. 1993), sheep (Battye et al. 1991), hamster (Velasquez et al. 1995) and human (Collier et al. 1990, Ammit \& O'Neill 1991, Nakatsuka et al. 1992). No embryos of marsupial species have yet been examined, although Paf appears to be produced by the endometrium of the tammar during the period of reactivation (Kojima et al. 1993). Similarly, PTAFR mRNA transcripts are expressed in the human blastocyst (Sharkey et al. 1995, Roudebush et al. 2003) and across all preimplantation stages in both porcine and mouse embryos (Roudebush et al. 1997, 2002, Stojanov \& O'Neill 1999, Lee et al. 2004).

Paf is beneficial for early embryonic development in a number of ways. In the mouse, the addition of Paf can stimulate embryo metabolism (Ryan et al. 1989, 1990a), increase total cell number (Ryan et al. 1990b, Roudebush et al. 1996) and promote overall embryo development and viability (Nishi et al. 1995, Stoddart et al. 1996, O'Neill 1997, 1998). Furthermore, Paf has the critical function of generating a pro-survival antiapoptotic transcriptome within the embryo (Jin \& $\mathrm{O}^{\prime}$ Neill 2011) and has the net effect of maintaining the tumour suppressor protein p53 in a latent state (Jin et al. 2009). However, exposure to high levels of Paf provides either no additional benefit or can even have harmful effects (Ryan et al. 1990b).
In the tammar, Paf is present in the culture medium after incubation of endometrial explants during embryonic diapause and at all reactivation stages examined (Kojima et al. 1993). Although Paf production is highly variable, its levels appear to increase at reactivation, around four days after RPY. This is a coincident with both the first observed pulse of progesterone and the first signs of reactivation and increased metabolism in the tammar blastocyst (Hinds \& Tyndale-Biscoe 1982, Gordon et al. 1988, Kojima et al. 1993, Spindler et al. 1998, 1999). However, it is unclear whether Paf is actively secreted by the endometrium or released as a result of collection techniques. Regardless, the release of Paf around the time of the progesterone pulse is consistent with reports on the rat and sheep, which indicate that endometrial Paf release is dependent on progesterone and/or oestradiol that, in the sheep, may occur in a pulsatile manner (Chami et al. 1999, 2004, Li et al. 1999). As Paf is an important regulator of embryo development in a wide range of eutherian species, and in tammars Paf secretion by the endometrium is increased at the time of reactivation from diapause, it is possible that the increased metabolic and mitotic rates observed in the tammar blastocyst at reactivation from diapause could be attributable to an increase in intrauterine Paf.

Although Paf has beneficial effects on the preimplantation embryo and the endometrium secretes Paf, surprisingly there is no direct, definitive evidence that Paf released from the endometrium acts directly on the embryo in any species, which implies that only autocrine Paf release affects embryo development (O'Neill 2005). In the tammar, it is not known whether Paf is produced and released by the embryo, nor do we know the distribution of PTAFR in either the endometrium or the embryo. In this study, we aimed to characterise the expression of PTAFR in the tammar endometrium and embryo at entry into diapause, during diapause and reactivation from diapause to determine whether endometrial Paf could function in reactivation of the blastocyst from embryonic diapause.

\section{Materials and methods}

\section{Animals}

Tammar wallabies (M. eugenii) of Kangaroo Island origin were kept in open grassy yards in our breeding colony. Their diet was supplemented with fresh fruit, vegetables and lucerne cubes, and water was supplied ad libitum. Care and treatment of animals conformed to the National Health and Medical Research Council Australian (2004) guidelines. All animal handling and experimentation was approved by the University of Melbourne Animal Experimentation Ethics Committees.

\section{Tissues}

Tammar uterine samples and embryos were obtained as previously described (Renfree \& Tyndale-Biscoe 1978). 
Other tissues were collected from the pouch young (days 0-350 post-partum) for use as positive controls as listed below. When the day of birth was unknown, the ages of pouch young were extrapolated from growth curves based on head length measurements (Poole et al. 1991). Before and during embryonic diapause, the stage of pregnancy was based on the post-partum age of the pouch young. The tammar has a post-partum oestrus and the sucking stimulus of the pouch young acts to inhibit luteal development via prolactin secreted from the pituitary (reviewed in Tyndale-Biscoe \& Renfree (1987)). This luteal inhibition prevents the progesterone pulse from occurring and results in the endometrium and subsequently the embryo entering into quiescence (Tyndale-Biscoe 1978, Shaw \& Renfree 1986, Renfree \& Shaw 2000). In this study, adult females with a pouch young older than day 8 post-partum were presumed to be carrying a diapausing blastocyst (Tyndale-Biscoe \& Renfree 1987). Before reactivation from diapause can occur, the pouch younginduced luteal inhibition must be removed for 3 consecutive days (Gordon et al. 1988, Hinds 1989). Therefore, after diapause the reactivation stages of pregnancy were determined relative to the day of RPY (day 0; Fig. 1).

All tissues were collected under RNase-free conditions. Tissues were either snap frozen in liquid nitrogen for RNA and/or protein extraction or fixed overnight in $4 \%(\mathrm{w} / \mathrm{v})$ paraformaldehyde, washed twice in $1 \times$ PBS and stored in $70 \%(\mathrm{v} / \mathrm{v})$ ethanol before paraffin embedding and sectioning.

\section{Cloning of tammar PTAFR partial cDNA sequences}

Total RNA was isolated from pouch young tissues with TRI Reagent (Ambion, Austin, TX, USA) and DNase-treated using DNA-free (Ambion) according to the manufacturer's instructions. The quality and quantity of the RNA were verified by both electrophoresis and optical density reading using a NanoDrop ND-1000 spectrophotometer (BioLab, Thermo Fisher Scientific, Waltham, MA, USA). Five micrograms total RNA were reverse transcribed using SuperScript III Kit (Invitrogen) with oligo(dT) priming according to the manufacturer's instructions. Cross species primers designed to conserved regions were initially used to amplify partial sequences of PTAFR from day 80 post-partum liver. The PCR products were cloned using the pGEM-T-Easy vector (Promega) and sequenced at the Sequencing and Genotyping Facility (Department of Pathology, University of Melbourne, Australia). The resulting sequence was used to design tammar-specific primers for the expression study (see below). The specificity of all transcripts obtained was confirmed by homology with nucleotide sequences using the National Centre for Biotechnology Information (NCBI) BLASTN 2.2.26 program (www.ncbi.nlm.nih.gov/BLAST/). Once the tammar genome had been released, the cloned partial sequence obtained was combined with the corresponding partial sequence available on Ensembl (www. ensembl.org, Ensembl release 67, May 2012). The remainder of the sequence was then obtained by sequence searches of the tammar Whole Genome Shotgun (WGS) database available at $\mathrm{NCBI}$ and contigs were aligned using CAP3 (Huang \& Madan 1999). The predicted protein sequence for the full-length tammar PTAFR was obtained using the Translate tool from the Swiss Institute of Bioinformatics (SIB) ExPASy Bioinformatics Resources Portal (Artimo et al. 2012). The tammar sequence was then compared against nucleotide and protein sequences from human, mouse, opossum, Tasmanian devil and platypus sequences retrieved from either GenBank (www.ncbi.nlm.nih.gov/) or Ensembl (relevant accession numbers are listed in Table 1). Nucleotide and protein identities were determined using FASTA (version 36.3.5c, March 2012; Pearson \& Lipman 1988) and the protein alignment was determined using T-Coffee (Notredame et al. 2000, Tommaso et al. 2011). The cloned tammar PTAFR nucleotide sequence has been submitted to GenBank (GenBank ID: JX524197).

\section{Endometrial qPCR expression}

In order to determine the variation in the expression for PTAFR in the endometrium across the stages of embryonic diapause, total RNA was isolated from the endometrium as described earlier. Oligo(dT)-primed first-strand cDNA synthesis was reverse transcribed from $3 \mu \mathrm{g}$ of total RNA in a $20 \mu \mathrm{l}$ reaction using TaqMan (Roche Molecular Systems, Inc. and Applied Biosystems) following the manufacturer's instructions and diluted 1:5 with nuclease-free water. QPCR was performed in a $20 \mu \mathrm{l}$ reaction volume using $5 \mu \mathrm{l}$ cDNA, $10 \mu \mathrm{l}$ QuantiTect SYBR Green PCR Kit (Qiagen) and $0.8 \mu \mathrm{m}$ of each primer. The relative expression levels of PTAFR transcripts were compared with the reference gene ACTB using the following tammar-specific primers: PTAFR (forward, 5'-CCTTGTTGAGTCAGCCTCTT-3'; reverse, 5'-CGTGTCCATCAGTACATCA-3 ${ }^{\prime}$ ) and ACTB (forward, $5^{\prime}$-TTGCTGACAGGATGCAGAAG-3'; reverse $5^{\prime}$-AAAGCCATGCCAATCTCATC- $3^{\prime}$ ).

Reactions were run in triplicate on an Opticon 2 (M) Research, Waltham, MA, USA) using the following conditions: $50{ }^{\circ} \mathrm{C}, 10 \mathrm{~min} ; 95^{\circ} \mathrm{C}$, $15 \mathrm{~min} ; 50$ cycles of $95^{\circ} \mathrm{C}, 30 \mathrm{~s} ; 53^{\circ} \mathrm{C}$, $30 \mathrm{~s} ; 72{ }^{\circ} \mathrm{C}, 40 \mathrm{~s}$ and a plate read for $1 \mathrm{~s} ; 72{ }^{\circ} \mathrm{C}$ for $1 \mathrm{~min}$ and a dissociation curve from 55 to $95^{\circ} \mathrm{C}$, reading for $1 \mathrm{~s}$ every $0.5^{\circ} \mathrm{C}$ and a final extension of $72{ }^{\circ} \mathrm{C}$ for $5 \mathrm{~min}$. A minimum of five

Table 1 Homologies for tammar PTAFR nucleotide and protein sequence compared with other vertebrates.

\begin{tabular}{|c|c|c|c|c|}
\hline $\begin{array}{l}\text { Common } \\
\text { names }\end{array}$ & $\begin{array}{l}\text { Species } \\
\text { names }\end{array}$ & $\begin{array}{l}\text { Accession } \\
\text { numbers }\end{array}$ & $\begin{array}{l}\text { Nucleotide } \\
\text { identities }(\%)^{\mathrm{a}}\end{array}$ & $\begin{array}{c}\text { Protein } \\
\text { identities }(\%)^{\mathrm{b}}\end{array}$ \\
\hline Human & $\begin{array}{l}\text { Homo } \\
\text { sapiens }\end{array}$ & $\begin{array}{r}\text { NM_0011 } \\
6 \overline{4} 723.2\end{array}$ & 75 & $75(89)$ \\
\hline Mouse & $\begin{array}{l}\text { Mus } \\
\quad \text { musculus }\end{array}$ & $\begin{array}{r}\text { NM_0010 } \\
81211.1\end{array}$ & 69 & 71 (89) \\
\hline $\begin{array}{l}\text { Grey short } \\
\text { tailed } \\
\text { opossum }\end{array}$ & $\begin{array}{c}\text { Monodelphis } \\
\text { domestica }\end{array}$ & $\begin{array}{l}\text { XM_0013 } \\
72834.1\end{array}$ & 83 & 81 (93) \\
\hline $\begin{array}{l}\text { Tasmanian } \\
\text { devil }\end{array}$ & $\begin{array}{l}\text { Sarcophilus } \\
\text { harrissi }\end{array}$ & $\begin{array}{c}\text { ENSSHA- } \\
\text { T00000- } \\
003177\end{array}$ & 85 & 85 (94) \\
\hline Platypus & $\begin{array}{l}\text { Orintho- } \\
\text { rynchus } \\
\text { anatinus }\end{array}$ & $\begin{array}{r}\text { XM_0015 } \\
08993.2\end{array}$ & 71 & 71 (86) \\
\hline
\end{tabular}

${ }^{a}$ Only the coding sequence for each gene was compared with the tammar sequence. ${ }^{b}$ Values in brackets are the percentage amino acid similarity with tammar PTAFR. 
replicates were run per stage for a total of ten stages covering entry into diapause, diapause and reactivation from diapause. The negative control reactions contained nuclease-free water instead of template. Plates were excluded if more than one of the negative control triplicates was contaminated. Individual samples of a triplicate were also excluded if they had irregular melting curves or if the coefficient of variation (CV) was $>0.05$ for the triplicate and the remaining two samples had a CV of $<0.05$. If more than one of the triplicates was irregular, the sample was repeated or excluded.

The expression levels of PTAFR transcripts were compared with the expression levels of $A C T B$ using the $\Delta \Delta C$ t method to correct the Ct values (Livak \& Schmittgen 2001). The subsequent relative quantity values obtained for the replicates of each stage were then averaged and analysed as described below.

\section{Embryo RT-PCR expression}

In order to check the expression pattern of PTAFR in the embryo across the stages of embryonic diapause, total RNA was isolated from embryos using the RNeasy Plus Micro Kit (Qiagen) with adjustments as described in a study by Lefèvre \& Murphy (2009). cDNA was reverse transcribed from total RNA using the SMARTer PCR cDNA synthesis kit (Clontech) and then amplified using Ex Taq polymerase (Takara, Shiga, Japan) for 27 cycles. RT-PCR was performed in a $25 \mu \mathrm{l}$ reaction with GoTaq Green Master Mix (Promega) with $0.3 \mu \mathrm{M}$ of each forward and reverse primer using the same PTAFR primers as for qPCR but using GAPDH as the reference gene, because in the tammar we have found $G A P D H$ to have a more consistent expression in the embryo than $A C T B$. Primer sequences were GAPDH (forward, 5'-CCTACTCCAATGTATCTGTTGT-3'; reverse, 5'-GGTGGAACTCCTTTTTTGACTGG-3'). RT-PCR conditions were $95^{\circ} \mathrm{C}, 2 \mathrm{~min} ; 40$ cycles of $95^{\circ} \mathrm{C}$, $30 \mathrm{~s} ; 53^{\circ} \mathrm{C}$, $60 \mathrm{~s} ; 72{ }^{\circ} \mathrm{C}, 1 \mathrm{~min}$, then $72{ }^{\circ} \mathrm{C}$ for $5 \mathrm{~min}$. The negative control reaction contained nuclease-free water instead of template and a day 3 post-partum gravid endometrial sample served as a positive control.

\section{Endometrial protein expression}

Protein expression and localisation of PTAFR in the endometrium was carried out using immunohistochemistry across a range of 16 gravid uterine stages covering entry into diapause (seven stages, days 0-8 post-partum), early and late diapause (five stages, days 9-250 post-partum) and reactivation from diapause (four stages, days 3-6 RPY) with three replicates per stage. Each immunohistochemistry run included one uterine tissue at each stage with day 175 post-partum lung used as a positive control (initially used to confirm antibody specificity) to ensure consistency in each run. Tissue sections $(6 \mu \mathrm{m})$ were prepared as described earlier, deparaffinised and rehydrated. Sections were treated with $5 \%(\mathrm{v} / \mathrm{v})$ hydrogen peroxide in distilled water for 15 min to block endogenous peroxidases and then washed in Tris-buffered saline with Tween-20 (TBST) containing $100 \mathrm{mM}$ Tris- $\mathrm{HCl}, \mathrm{pH} 7.5,300 \mathrm{mM} \mathrm{NaCl}$ and $0.5 \%$ $(\mathrm{v} / \mathrm{v})$ Tween-20. The sections were blocked with $10 \%(\mathrm{v} / \mathrm{v})$ goat serum with $0.1 \%(\mathrm{w} / \mathrm{v})$ BSA (Sigma-Aldrich) in TBST (diluent) for $1 \mathrm{~h}$, and then incubated overnight at $4{ }^{\circ} \mathrm{C}$ with primary antibody. PTAFR was detected with a rabbit polyclonal antibody (160602, Cayman Chemical Company, Ann Arbor, MI, USA) at a concentration of $2 \mu \mathrm{g} / \mathrm{ml}$. The next day, sections were washed in TBST, incubated for $1 \mathrm{~h}$ in polyclonal goat anti-rabbit-biotinylated secondary antibody (E0432, Dako, Glostrup, Denmark) at a concentration of $1.44 \mu \mathrm{g} / \mathrm{ml}$ and washed again in TBST. The signal was then amplified for $30 \mathrm{~min}$ with streptavidin/HRP conjugated (P0397, Dako) before a final wash in TBST. The signal was visualised with 3,3'-diaminobenzidine (Dako) and sections were counterstained with haematoxylin. Two negative controls were also included on every slide in every run, diluent only and rabbit IgG fraction (normal) (X0903, Dako) at the same concentration as the primary antibody.

\section{Embryo immunofluorescence}

Embryo whole-mount immunofluorescence was performed to detect PTAFR across the stages of entry into diapause (days 2-4 post-partum), early and late diapause (days 11-250 postpartum) and reactivation from diapause (day 4 RPY). Three replicates from each stage of diapause were tested along with three negative IgG control embryos (day 6 post-partum, day 189 post-partum or day 3 RPY), where each immunofluorescence run consisted of one embryo from each stage and one negative IgG control embryo. Immunofluorescence used the same primary antibody and IgG listed earlier for the immunohistochemistry. Embryo shell coats were first removed to prevent autofluorescence and then embryos were washed in wash buffer $(0.05 \%(\mathrm{v} / \mathrm{v})$ Tween-20 and $2 \%(\mathrm{w} / \mathrm{v})$ BSA in $1 \times$ PBS) before being permeabilised in $0.5 \%$ Triton $X-100(\mathrm{v} / \mathrm{v})$ in $1 \times$ PBS for $30 \mathrm{~min}$. Embryos were washed as mentioned earlier and then blocked in 30\% (v/v) donkey serum (D9663, Sigma-Aldrich) for 2-3 h. After blocking, embryos were incubated overnight for at least $16 \mathrm{~h}$ with either primary antibody at $1 \mu \mathrm{g} / \mathrm{ml}$ or rabbit non-immune IgG fraction (normal) (X0903, Dako) (at the same concentration as primary antibody). The next day, embryos were washed as above and then incubated with AF488 donkey anti-rabbit secondary IgG antibody (A21206, Invitrogen) at $10 \mu \mathrm{g} / \mathrm{ml}$ for $1 \mathrm{~h}$ in the dark at room temperature; embryos were kept in the dark from this point. Embryos were then washed as above and incubated with $100 \mathrm{ng} / \mathrm{ml}$ DAPI dilactate (D3571, Invitrogen) in PBS for 5 min, washed again and mounted in DABCO antifade (1,4-diazabicyclo[2.2.2] octane).

\section{Confocal microscopy}

Embryos were visualised using the Zeiss LSM 510 Meta Confocal Microscope (Carl Zeiss, Jena, Germany) mounted on a Zeiss Axioplan (Imager.Z1/I AXIO) upright microscope and images were captured using the attached Zen 2009 LE program. Embryos were visualised with Argon (Green Alexafluor 488 antibody) and u.v. (DAPI). Pinhole diameter was set as close as possible to 1.5 Airy units on the weaker Argon channel, and the pinhole diameter was then kept constant in the u.v. settings. Visualisation using maximal gain and offset was able to be optimised separately for each channel. Each run contained an IgG control embryo and visualisation settings were initially optimised to eliminate background using 
this control embryo to reduce the Argon settings until staining was minimal. These settings were then used to visualise the other embryos in the run. Embryo images were captured using a $z$-stack of both channels throughout the whole embryo with optical slices taken approximately every $5 \mu \mathrm{m}$.

\section{Western blot}

Protein for the western blots was extracted from snap frozen tissue using radioimmunoprecipitation buffer with a mix of protease inhibitors (Protease Inhibitor Cocktail Set V, Calbiochem, \#535141; Merck, Darmstadt, Germany). Protein concentrations were measured with a spectrophotometer (NanoDrop ND-1000, BioLab), diluted in $4 \times$ Laemmli sample buffer with $5 \%$ (v/v) $\beta$-mercaptoethanol (Laemmli 1970) and heated for $5 \mathrm{~min}$ at $100^{\circ} \mathrm{C}$. PTAFR $(48 \mathrm{kDa})$ was run across $25 \mu \mathrm{g}$ protein samples of day 156 post-partum lung, day 170 post-partum liver, day 138 post-partum kidney and adult day 5 RPY gravid endometrium. Protein samples were run on a $10 \%$ SDS-PAGE separating gel and blotted to a PVDF Hybond-P membrane (Amersham, GE Healthcare, Buckinghamshire, UK). The membrane was blocked with $5 \%(\mathrm{w} / \mathrm{v})$ skim milk in TBST (containing $200 \mathrm{mM}$ Tris- $\mathrm{HCl}, \mathrm{pH} 7.5,300 \mathrm{mM} \mathrm{NaCl}$ and $0.1 \%(\mathrm{v} / \mathrm{v})$ Tween-20) for $16 \mathrm{~h}$ at $4{ }^{\circ} \mathrm{C}$ and then incubated with $2 \mu \mathrm{g} / \mathrm{ml}$ primary antibody for $1 \mathrm{~h}$. The membrane was then washed three times in TBST for 10 min each, incubated with HRP-conjugated secondary antibody goat anti-rabbit (sc-2004, Santa Cruz Biotechnology, Inc.) at $0.04 \mu \mathrm{g} / \mathrm{ml}$ for $30 \mathrm{~min}$ and washed again as mentioned earlier. Protein bands were detected using chemiluminescence, where the membrane was incubated with ECL western blotting detection reagents (RPN2106, GE Healthcare) for $1 \mathrm{~min}$ and exposed to Hyperfilm (Amersham, GE Healthcare) for $10 \mathrm{~min}$.

\section{Statistical analysis}

Statistical analyses for qPCR were conducted using $R$, version 2.11.1 (R Development Core Team 2010). For all analyses, a significance level of $P<0.05$ was used and data are presented as mean \pm s.E.M. A Shapiro-Wilks test was first performed to check the assumption that the data had a normal distribution. As the distribution of the relative expression values was skewed, the data were log transformed for analysis and the back-transformed means were reported. Log transformed data were analysed by one-way ANOVA, with multiple comparisons of means compared using Tukey contrasts (only if ANOVA was significant). As there was no significant variation with age, samples were further grouped as 'entry into diapause', 'during diapause' and 'reactivation from diapause' and one-way ANOVA was performed as described earlier.

\section{Results}

\section{Cloning and sequence analysis of the tammar PTAFR gene}

An 801-bp partial PTAFR cDNA sequence was obtained with cross-species primers which, when combined with the partial PTAFR sequence available on Ensembl
(ENSMEUT00000006792), partially overlapped with and extended the sequence to $904 \mathrm{bp}$. This sequence was then used to search the tammar wallaby WGS database (available at NCBI) to identify the remainder of the $3^{\prime}$ end of the tammar PTAFR sequence. The contigs obtained (ti, 1484702988; ti, 1709030349; ti, 1646286453 and ti, 1648958551) overlapped with and extended the above sequence by $131 \mathrm{bp}$. The whole coding region of the PTAFR gene is contained within only one exon. The full tammar coding sequence was $1035 \mathrm{bp}$ in length and the translated sequence predicted a protein of 344 amino acids. There was moderately high conservation of tammar PTAFR with all mammalian vertebrates examined with nucleotide sequence identities of $69 \%$ or greater (Table 1). The protein sequence identities were also highly conserved between tammar PTAFR and other mammals, and showed a very high amino acid similarity (Table 1 ). Although the predicted tammar protein sequence contained a number of sequence variations compared with the eutherians, the majority of these were conserved in both opossum (Monodelphis domestica) and Tasmanian devil (Sarcophilus harrissi) (Fig. 2).

Consistent with the structure of a G protein-coupled receptor, PTAFR consists of an extracellular $\mathrm{N}$-terminal domain, an intracellular C-terminal domain and seven transmembrane domains intersected by an additional three extracellular and three cytoplasmic domains (Prescott et al. 2000, Ishii et al. 2002). In the tammar, the transmembrane domains had the highest conservation with eutherians and these were also highly conserved among all marsupial species. Based on mutation studies, transmembrane domains 5, 6 and 7 are predicted to be involved in Paf binding and, in particular, three histidine residues are thought to constitute the three-dimensional Paf-binding pocket and were completely conserved in the tammar (Ishii et al. 1997). Other regions important for PTAFR function that were conserved in the tammar include the third intracellular loop, which is required for intracellular signalling, and the C-terminal domain, which is phosphorylated before desensitisation of the receptor (Prescott et al. 2000).

\section{mRNA expression profiles for PTAFR in the endo- metrium and embryo during embryonic diapause}

Endometrial PTAFR mRNA was detected by RT-PCR before, during and after embryonic diapause (Fig. 3A). The expression of PTAFR in endometrium during these stages did not vary quantitatively when assessed by qPCR expression (Fig. 3B; $P>0.05$ ) and there was no significant difference in PTAFR expression in the endometrium between entry into diapause, diapause and reactivation from diapause (Fig. 3B; $P>0.05$ ). PTAFR was also detected in the embryo at all stages examined (Fig. 3C). 
Human

$1 \mathrm{M}$ PH--DSSHMDSEFRYT LFPIVYSI IFVLGVIANGYVLW VFARLYPCKKFNEIKIFMVN

Mouse

Tammar

Opossum

Devil

Platypus

$1 \mathrm{M} \boxminus$ HN - -GSFRVDSEFRYTLFPIVYSVIFILG

ANGYVLW VFANLYP SKKLNEIKI FMVN

1 MVDGE--NSRVDSEFRYT LFPIVYGI I FVLGT ISNGYVLWVFISLNRAKKLNEI KI FMVN

1 MD-ED--NFRIDSEFRYTLFP IVYSI I FVLGFV SNAYVLWVFI SDPSKKLNEIKIFMVN

1 MMDEK-NSDR IDSEFRYTLIPIVYSI I FVLG I SNGYVLW VFV LNPAKKLNEI KI FMVN

1 MSPGPNTIRRVDSEFRYTLFPVAYSI I FVLG FANGYVLWVFARLYP KKLNEI KI FMVN

TM3

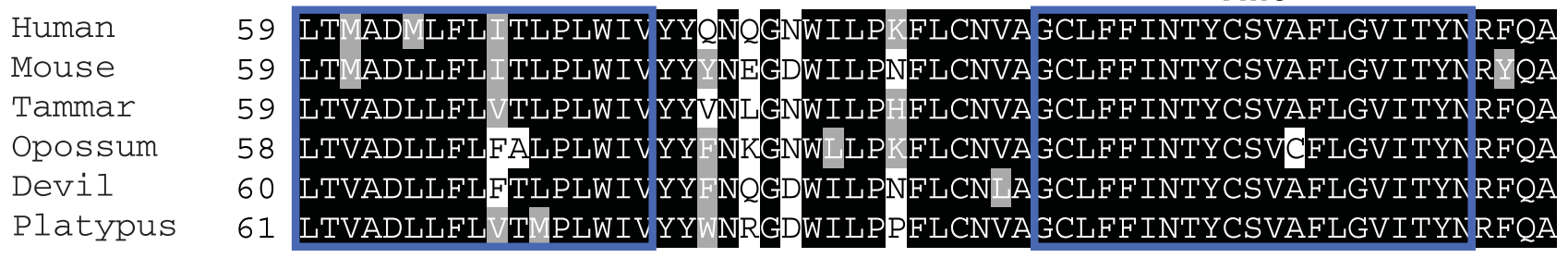

TM4

Human $\quad 119$ VTRPIKTAQANTRKR GISLSLVIWVAIVGAASYFLILD STNTVPDSAGSGNVTRCFEHYE Mouse $\quad 119$ VAYPIKTAQATTRKR GISLSLIIWVSIVATASYFLATI STN VPNKDGSGNITRCFEHYE Tammar 119 VTDPITAAQSTTRRR GIILSLIIWVVIVGCASYFLFLF STNMVSLKE-GKNVTRCFEHYE Opossum 118 VTDPIKAAQSTTRRR GI LSTI IWVVIVGCASYFLISI ATNSVPSKMTGENVTRCFEHYE Devil 120 VTDPIKAAQSTTRRR GIILSLIIWVVIVGCALYFLILISTNVVLLKTGG NNTRCFENYE Platypus 121 VTRPIKAAQATTRKRGIVLSLVIWVLIVSSALYFLVA GTNIAIEAS-GRNVTRCFESYE 1 TM5

TM6

Human

Mouse

Tammar

Opossum

Devil

Platypus

179 KCS

179 PYSVPILVVHVFIAFCFF

178 ERSIPVLIIHVIIVFCVF

178 KGSIPVLIHVFIVLCFF 180 KGS I PVLI IHIIIVFCFF IVFLVILVCNAI I IRTLLAQPLQPQS - -NANVKHKALWM VCT

VFLIILFC NLVI IRTLLMQP QQQQR - -NAEVKRRALWM VCT $180 \mathrm{KDSQAV}$ ¿AIHIF IVASFFAVFLILVCNLTI I HMLLAQPSQAQSVRGAGVKSRALWM VCT لI

TM7

Human

Mouse

Tammar

Opossum

Devil

Platypus

237

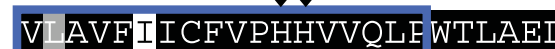

- GFQD-STFHQ

A INDAHC VTLCL STNCVLDP VIY

237 V AVFIICFVPHHVVQLE WTLAEL - GYQT - -NFHQ INDAHC ITLCL

236 VMAVFFICFVPHHIVQLEWTLAELKM GFK SKRVHQY INDAHC VTLCL

236 VMAVFFICFVPHHVVQLEWTLAELQI GFQ NDQVHQLINDAHC VTLCL

238 VMAVFFICFVPHHI IQLF WTVAELKI GFOGNSRVHQCINDIHC VTLCL

STNCVLDPVIY

VLAVFIICFVPHHVVQLE WTLAEV - - KWHN - HRSHQ

INDAHC VTLCL STNCVLDPVIY

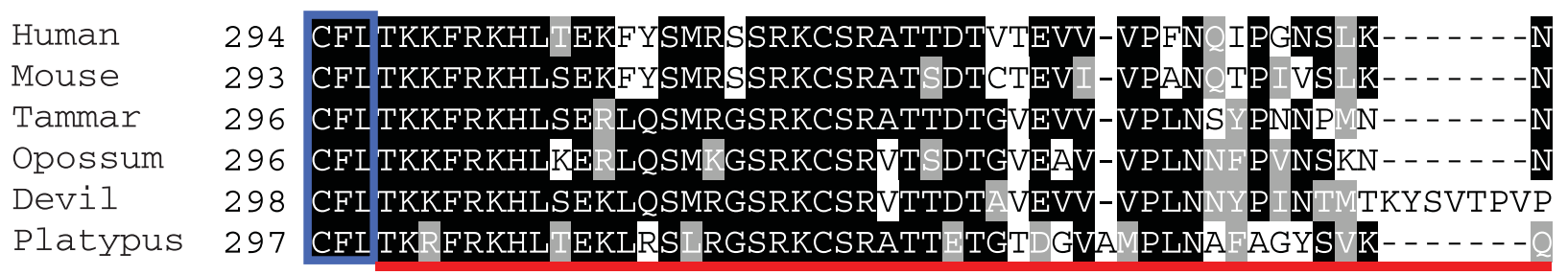

Figure 2 Alignment of the predicted tammar PTAFR sequence with PTAFR from other species. Wallaby PTAFR was highly conserved with known mammalian vertebrates. In particular, the seven transmembrane domains (blue boxes) showed the highest conservation across species and this included conservation of the three histidine residues that are predicted to form the Paf-binding pocket (arrows). Shown here also are the third intracellular loop (underlined in yellow) and the C-terminal intracellular tail (underlined in red). Black backgrounds indicate identical residues of the consensus sequence, grey backgrounds indicate similar residues and white background indicates either no similarity to the consensus sequence or no consensus sequence could be obtained. 
A
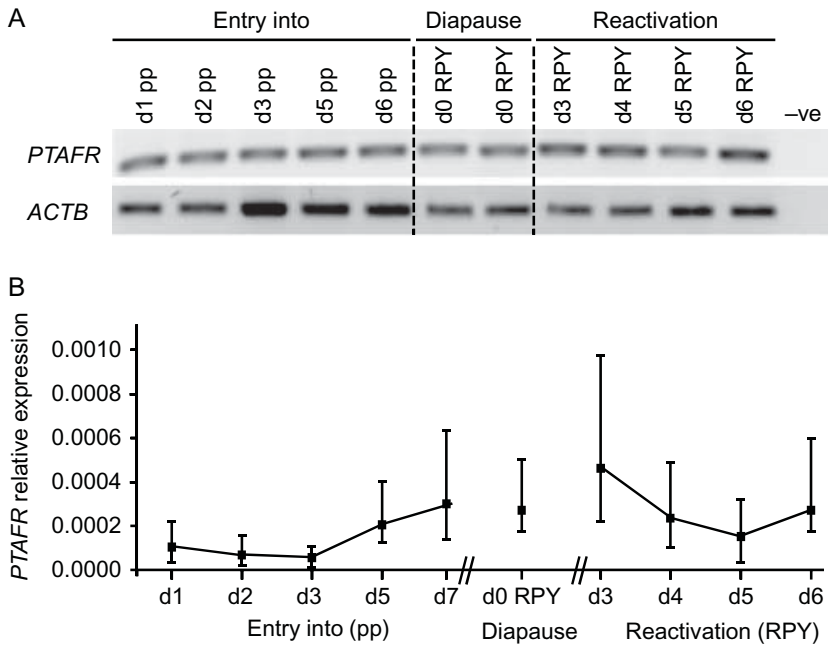

C

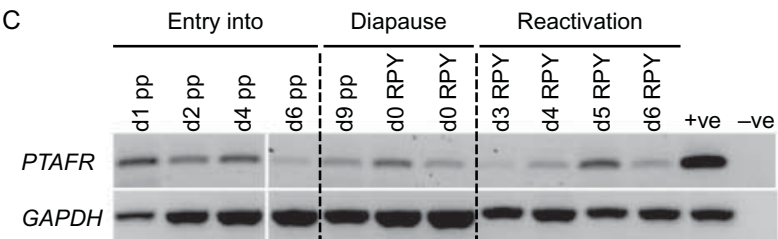

Figure 3 mRNA expression profiles of PTAFR in the embryo and the endometrium across the stages of entry into diapause, diapause and reactivation from diapause. (A) mRNA expression profile for PTAFR in the endometrium across the stages of entry into diapause, diapause and reactivation from diapause, showing expression at all stages. ACTB was used as the reference gene; (B) PTAFR qPCR endometrium expression profile relative to $A C T B$ showing consistent expression across all stages with no significant difference in expression at any stage. Data are mean \pm S.E.M. with $n=5$ samples per individual pregnancy stage except for diapause with $n=7$ samples; (C) PTAFR mRNA was expressed across all stages in the embryo from entry into diapause, diapause and reactivation from diapause. GAPDH was used as the reference gene. Note that the embryo RT-PCR image is formed from different parts of the same gel for each gene. + ve, positive control (day 3 post-partum gravid adult endometrium); - ve, no template negative control; $d$, day; $\mathrm{pp}$, post-partum; RPY, removal of pouch young.

\section{PTAFR protein expression in the uterus during embryonic diapause}

The protein expression and localisation of PTAFR in the uterus was examined by immunohistochemistry during entry into diapause, diapause and reactivation from diapause. At day 0 of pregnancy (which is also one day post-partum of the previous pregnancy), PTAFR staining was reduced in the glands (Fig. 4A) but at all other stages examined, including during entry into diapause, PTAFR was present predominantly on the membranes of the glandular epithelium (Fig. 4B, C and D). After reactivation, on day 4 RPY, there was a distinct apical staining in the basalis layer of the endometrium that was not present in the functionalis layer (Fig. 4D, inset shows basalis layer). Cytoplasmic staining in the luminal epithelium was first detected during embryonic diapause (Fig. 4C) and remained throughout reactivation (Fig. 4D). In the stroma, PTAFR staining was rare and detected only in some blood vessels; there was also occasional background cytoplasmic staining that was not consistent with stage. Furthermore, the presence of PTAFR staining in the pouch young lung (Fig. 4E) and its absence in the $\lg \mathrm{G}$ control (Fig. 4F) indicated that the expression observed in the uterus was not an artefact of the immunohistochemistry. In addition, a western blot confirmed that the antibody was specific to PTAFR and detected a protein of the expected size (Fig. 4G).

\section{Localisation of PTAFR protein expression in the embryo during embryonic diapause}

PTAFR protein expression and localisation was also examined in the embryo across the stages of entry into diapause, during diapause and reactivation from diapause. PTAFR protein was expressed strongly in the apical regions of the cells in the cleavage stage embryo before diapause (Fig. 5A), but there was a very
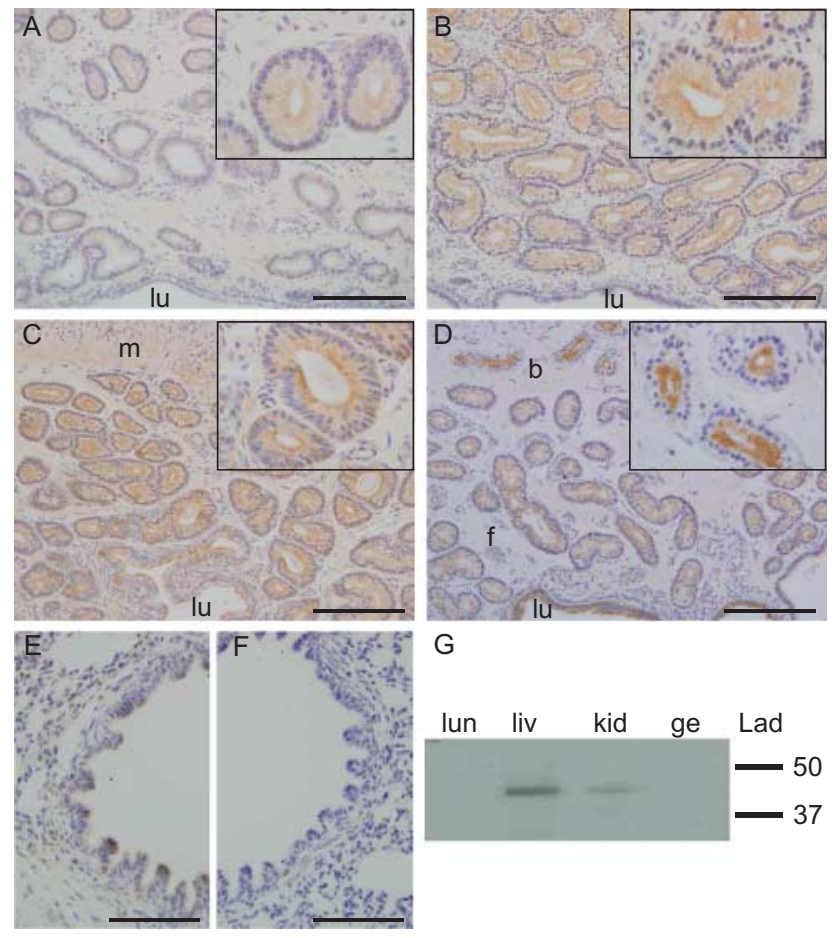

G

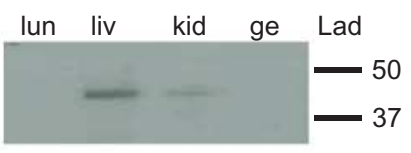

Figure 4 PTAFR protein is present in endometrial glands across all stages of embryonic diapause. PTAFR protein was detected in the endometrium across the stages of entry into embryonic diapause $(A$ and $B)$, during diapause $(C)$ and at reactivation from diapause (D). Inset shows high power of selected glands. Also shown is the positive control tissue, day 175 post-partum lung (E) and the $\operatorname{lgG}$ control for the same tissue (F). A western blot run for PTAFR (48 kDa), across a range of tissues determined the specificity of the antibody $(\mathrm{G})$. lu, lumen; $\mathrm{m}$, myometrium; b, basalis layer; $\mathrm{f}$, functionalis layer; lun, lung; liv, liver; kid, kidney; ge, gravid endometrium; Lad, ladder. Scale bar $(A, B, C$ and $D)=200 \mu \mathrm{m}$ at $20 \times$ magnification, $(E$ and $F)=100 \mu \mathrm{m}$ at $40 \times$ magnification, all insets are at $100 \times$ magnification. 


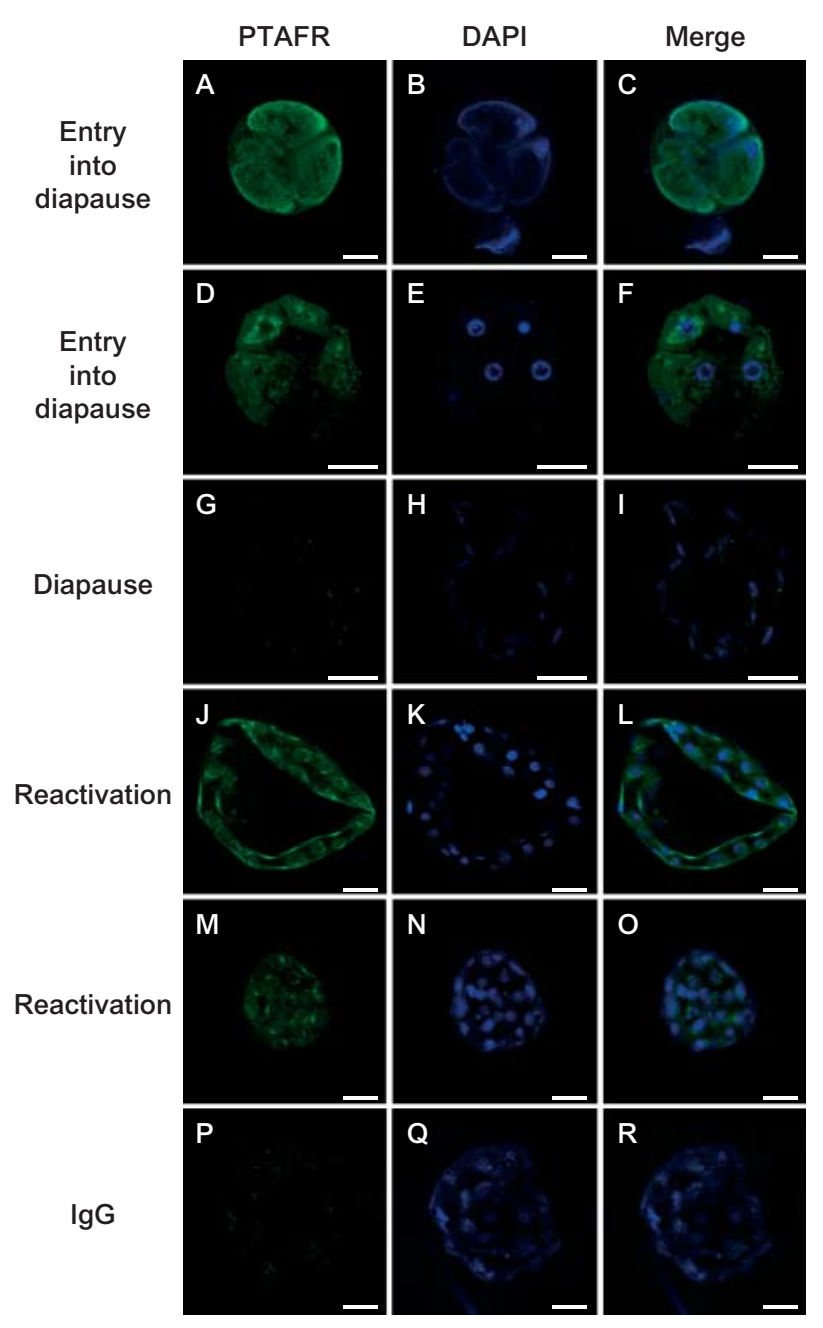

Figure 5 Representative sections showing PTAFR protein expression in the embryo across the stages of embryonic diapause. (A, B and C) Before diapause, a four-cell embryo showing strong PTAFR staining in the region of the cell membrane; (D, E and F) before diapause, an eight-cell embryo showing overall PTAFR staining and localised cytoplasmic expression; (G, H and I) during diapause, showing very faint PTAFR expression; (J, $\mathrm{K}$ and $\mathrm{L}$ ) reactivation from diapause, showing both membrane and cytoplasmic PTAFR expression; ( $M, N$ and $\mathrm{O}$ ) a view of the same reactivated embryo but through a different plane, showing the distinct localised cytoplasmic expression and (P, Q and R) the IgG negative control embryo. Embryos were visualised using a $z$-stack, photos shown are representative $5 \mu \mathrm{m}$ thick optical sections through the middle of the embryo, except for ( $M, N$ and $O)$ which is a section near the top of the embryo. Green indicates PTAFR, blue indicates DAPI nuclear stain and the merge shows both channels. Scale bar $=50 \mu \mathrm{m}$.

low (almost undetectable) expression in the blastocyst during embryonic diapause (Fig. 5G). At reactivation from diapause, there was strong staining in the region of the plasma membrane of several cells of the unilaminar blastocyst (Fig. 5J). There was also a localised cytoplasmic expression in the perinuclear region at both entry into diapause and reactivation (Fig. 5D, J and M).

\section{Discussion}

Successful reactivation from embryonic diapause in the tammar requires a progesterone pulse which induces active secretion from the endometrium (Hinds \& Tyndale-Biscoe 1982), but the factors involved in the molecular cross-talk between the endometrium and blastocyst are unknown. The results of this study suggest that endometrial Paf may be one of the important factors for the reactivation of the dormant tammar blastocyst.

The tammar PTAFR gene was highly conserved with that of PTAFR in eutherian species. Furthermore, the seven transmembrane domains were all highly conserved between tammar and all species examined, and this included conservation of the putative Paf-binding pocket (Ishii et al. 1997, Prescott et al. 2000). These domains are characteristic of a member of the G proteincoupled receptor superfamily and, together with conservation of the regions involved in translation of PTAFR signalling and desensitisation (Ishii \& Shimizu 2000, Prescott et al. 2000), suggest that the functional role of PTAFR has been conserved in the tammar.

There was no change in PTAFR expression in the tammar endometrium throughout any stage of diapause. Although in mice there are two Ptafr transcripts arising from two distinct promoters, the first exon of each is spliced to a common second exon so that both transcripts encode the same protein (Ishii \& Shimizu 2000). It was beyond the scope of this study to distinguish between the two transcripts and, as the PTAFR region examined contains the whole coding sequence, it is possible that dimorphic expression patterns exist for the two transcripts. However, in eutherians there is a correlation between PTAFR mRNA and PTAFR protein expression (Ahmed et al. 1998, Chami et al. 1999, 2004, Tiemann et al. 2005), thus the location of the protein is the critical factor in determining a biological effect.

PTAFR protein staining in the tammar endometrium was present in the glandular epithelium across all stages from day 2 post-partum, including throughout diapause and reactivation. Unexpectedly, PTAFR was first detected in the luminal epithelium during embryonic diapause and was subsequently intensely expressed at all reactivation stages examined. Although Paf is detected in the tammar endometrium at low levels during diapause (Kojima et al. 1993), the quiescent state of the endometrium at this time suggests that the effects of Paf are likely to be minimal.

Furthermore, the responsiveness of the tammar endometrium to Paf may require the progesterone pulse at reactivation. In the sheep, Paf can act as a pulse generator of uterine prostaglandins, but only in a steroid-primed uterus (Chami et al. 1999). Similarly, in humans, the response of the endometrium to Paf appears to depend on the steroid hormone profile and not on the cellular localisation of PTAFR (Ahmed et al. 1998). 
Consistent with this, at reactivation in the tammar endometrium there did appear to be a difference in PTAFR staining intensity between the basalis and functionalis layers of the endometrium. The low intensity staining within the glands of the functionalis layer suggested that the receptor is activated by the hormonally regulated Paf release at this time and is subsequently internalised and degraded, as is seen in other cell types (see below), but this remains to be established. Regardless, in the tammar, constant expression of PTAFR in the glandular epithelium at all stages and its presence in the luminal epithelium during both diapause and reactivation suggests that the expression of the receptor is not the limiting factor in mediating the response of the endometrium to Paf.

PTAFR mRNA was present in the tammar early embryo as in other eutherian species. This is the first report of PTAFR expression in a marsupial embryo. PTAFR was expressed throughout entry into diapause, diapause and reactivation, but qPCR analysis is required to determine a quantitative difference in expression between samples. In the mouse, Ptafr is first expressed after activation of the zygotic genome (Stojanov \& O'Neill 1999). Although it is not known when the tammar embryonic genome is activated, it would be expected to be active by the blastocyst stage. Thus these results indicate that PTAFR is presumably expressed from both the maternal and embryonic genomes.

In the embryo, PTAFR protein was strongly expressed at entry into diapause both in the region of the plasma membranes at the four-cell stage and with a distinct, localised cytoplasmic staining at the eight-cell stage. However, despite the presence of PTAFR mRNA, there was very low PTAFR protein detected during embryonic diapause. Hence, regulation of PTAFR expression in the tammar blastocyst appears to be at the protein level. At reactivation from diapause, in addition to the strong cellular membrane staining, there was again localised cytoplasmic staining suggesting that PTAFR was being internalised. Furthermore, this expression pattern did not appear to be localised to a particular area of the blastocyst. The tammar blastocyst has no inner cell mass and there are currently no methods to determine where the pluriblast cells of the embryo will form (Frankenberg et al. 2013). No cytoplasmic expression of this type has been reported in the embryos of eutherians, despite evidence that desensitisation occurs in response to Paf in the two-cell mouse embryo (Emerson et al. 2000) and that PTAFR can be internalised in other cell types. In Chinese hamster ovary cells, treatment with Paf results in receptor phosphorylation and sequestration into the cytoplasm (Ishii et al. 1998). Similarly, in a human cell line, Paf-stimulated PTAFR degradation is dependent on internalisation (Dupré et al. 2003). Therefore, it would appear that Paf is present both before diapause and at reactivation and is responsible for the internalisation of PTAFR observed at these stages.
Furthermore, the release of endometrial Paf appears to up-regulate PTAFR expression in the blastocyst at reactivation. However, the progesterone pulse at reactivation stimulates an overall increase in uterine secretions and the activity of these factors can significantly affect the timing of blastocyst reactivation (Shaw \& Renfree 1986, Spindler et al. 1998). Therefore, there are numerous other uterine factors present, whose downstream effects could result in an increase in blastocyst PTAFR levels. Regardless, these results support the suggestion that at reactivation, the progesterone pulse from the corpus luteum results in an increase in endometrial Paf which binds to, and is involved in, the reactivation of the tammar blastocyst from embryonic diapause.

\section{Declaration of interest}

The authors declare that there is no conflict of interest that could be perceived as prejudicing the impartiality of the research reported.

\section{Funding}

This study was supported by grants from the Australian Research Council.

\section{Acknowledgements}

We thank Kerry Martin, Alison Bradfield and Scott Brownlees for assistance with the wallabies and Helen Gehring for performing the majority of the endometrial RNA extractions.

\section{References}

National Health and Medical Research Council Australian guidelines 2004 Australian code of practice for the care and use of animals for scientific purposes.

Ahmed A, Dearn S, Shams M, Li XF, Sangha RK, Rola-Pleszczynski M \& Jiang J 1998 Localization, quantification, and activation of plateletactivating factor receptor in human endometrium during the menstrual cycle: PAF stimulates NO, VEGF, and FAKpp125. FASEB Journal 12 831-843.

Ammit AJ \& O'Neill C 1991 Comparison of a radioimmunoassay and bioassay for embryo-derived platelet-activating factor. Human Reproduction 6 872-878.

Artimo P, Jonnalagedda M, Arnold K, Baratin D, Csardi G, Castro ED, Duvaud S, Flegel V, Fortier A, Gasteiger E et al. 2012 ExPASY: SIB bioinformatics resource portal. Nucleic Acids Research 40 W597-W603. (doi:10.1093/nar/gks400)

Battye KM, Ammit AJ, O'Neill C \& Evans G 1991 Production of plateletactivating factor by the pre-implantation sheep embryo. Journal of Reproduction and Fertility 93 507-514. (doi:10.1530/jrf.0.0930507)

Chami O, Megevand A, Ott T, Bazer F \& O'Neill C 1999 Platelet-activating factor may act as an endogenous pulse generator for sheep of luteolytic $\mathrm{PGF}_{2 \alpha}$ release. American Journal of Physiology. Endocrinology and Metabolism 276 E783-E792.

Chami O, Evans G \& O'Neill C 2004 Components of a platelet-activating factor-signaling loop are assembled in the ovine endometrium late in the estrous cycle. American Journal of Physiology. Endocrinology and Metabolism 287 E233-E240. (doi:10.1152/ajpendo.00323.2003) 
Collier M, O'Neill C, Ammit AJ \& Saunders DM 1990 Measurement of human embryo-derived platelet-activating factor (PAF) using a quantitative bioassay of platelet aggregation. Human Reproduction 5 323-328.

Dupré DJ, Chen Z, Gouill CL, Thériault C, Parent J-L, Rola-Pleszczynski M \& Stankova J 2003 Trafficking, ubiquitination, and down-regulation of the human platelet-activating factor receptor. Journal of Biological Chemistry 278 48228-48235. (doi:10.1074/jbc.M304082200)

Emerson M, Travis AR, Bathgate R, Stojanov T, Cook DI, Harding E, Lu DP \& O'Neill C 2000 Characterisation and functional significance of calcium transients in the 2-cell mouse embryo induced by an autocrine growth factor. Journal of Biological Chemistry 275 21905-21913. (doi:10.1074/jbc.M001719200)

Frankenberg S, Shaw G, Freyer C, Pask AJ \& Renfree MB 2013 Early cell lineage specification in a marsupial: a case for diverse mechanisms among mammals. Development 140 965-975. (doi:10.1242/dev. 091629)

Gordon K, Fletcher TP \& Renfree MB 1988 Reactivation of the quiescent corpus luteum and diapausing embryo after temporary removal of the sucking stimulus in the tammar wallaby (Macropus eugenii). Journal of Reproduction and Fertility 83 401-406. (doi:10.1530/jrf.0.0830401)

Hinds LA 1989 Morning pulse of prolactin maintains seasonal quiescence in the tammar, Macropus eugenii. Journal of Reproduction and Fertility 87 735-744. (doi:10.1530/jrf.0.0870735)

Hinds LA \& Tyndale-Biscoe CH 1982 Plasma progesterone levels in the pregnant and non-pregnant tammar, Macropus eugenii. Journal of Endocrinology 93 99-107. (doi:10.1677/joe.0.0930099)

Hinds LA, Evans SM \& Tyndale-Biscoe CH 1983 In-vitro secretion of progesterone by the corpus luteum of the tammar wallaby, Macropus eugenii. Journal of Reproduction and Fertility 67 57-63. (doi:10.1530/jrf. $0.0670057)$

Huang X \& Madan A 1999 CAP3: a DNA sequence assembly program. Genome Research 9 868-877. (doi:10.1101/gr.9.9.868)

Ishii S \& Shimizu T 2000 Platelet-activating factor (PAF) receptor and genetically engineered PAF receptor mutant mice. Progress in Lipid Research 39 41-82. (doi:10.1016/S0163-7827(99)00016-8)

Ishii I, Izumi T, Tsukamoto H, Umeyama H, Ui M \& Shimizu T 1997 Alanine exchange of polar amino acids in the transmembrane domains of a platelet-activating factor receptor generated both constitutively active and inactive mutants. Journal of Biological Chemistry 272 7846-7854. (doi:10.1074/jbc.272.12.7846)

Ishii I, Saito E, Izumi T, Ui M \& Shimizu T 1998 Agonist-induced sequestration, recycling, and resensitization of platelet-activating factor receptor. Journal of Biological Chemistry 273 9878-9885. (doi:10.1074/ jbc.273.16.9878)

Ishii S, Nagase T \& Shimizu T 2002 Platelet-activating factor receptor. Prostaglandins \& Other Lipid Mediators 68-69 599-609. (doi:10.1016/ S0090-6980(02)00058-8)

Jin XL \& $\mathbf{O}^{\prime}$ Neill C 2011 Regulation of the expression of proto-oncogenes by autocrine embryotrophins in the early mouse embryo. Biology of Reproduction 84 1216-1224. (doi:10.1095/biolreprod.110.087007)

Jin XL, Chandrakanthan V, Morgan HD \& O'Neill C 2009 Preimplantation embryo development in the mouse requires the latency of TRP53 expression, which is induced by a ligand-activated PI3 kinase/ Akt/MDM2-mediated signaling pathway. Biology of Reproduction $\mathbf{8 0}$ 286-294. (doi:10.1095/biolreprod.108.070102)

Kojima T, Hinds LA, Muller WJ, O'Neill C \& Tyndale-Biscoe CH 1993 Production and secretion of progesterone in vitro and presence of platelet activating factor (PAF) in early pregnancy of the marsupial, Macropus eugenii. Reproduction, Fertility, and Development 5 15-25. (doi:10.1071/RD9930015)

Laemmli UK 1970 Cleavage of structural proteins during the assembly of the head of the bacteriophage T4. Nature 227 680-685. (doi:10.1038/ 227680a0)

Lee SH, Kim DY, Nam DH, Hyun SH, Lee GS, Kim HS, Lee C-K, Kang SK, Lee BC \& Hwang WS 2004 Role of messenger RNA expression of platelet activating factor and its receptor in porcine in vitro-fertilised and cloned embryo development. Biology of Reproduction 71 919-925. (doi:10.1095/biolreprod.103.026138)

Lefèvre PLC \& Murphy BD 2009. Differential gene expression in the uterus and blastocyst during the reactivation of embryo development in a model of delayed implantation. In Human Embryogenesis: Methods and Protocols, pp 11-61. Eds J Lafond and C Vaillancourt. New York: Humana Press (doi:10.1007/978-1-60327-009-0_2)

Li L, Yasuda K, Matsubara T, Okada H, Nakajima T, Sanezumi M \& Kanzaki H 1999 Estrogen effects on platelet-activating factor and platelet-activating factor acetylhydrolase activity in rat uterus during the late stages of pregnancy. Prostaglandins \& Other Lipid Mediators 57 219-230. (doi:10.1016/S0090-6980(99)00005-2)

Livak KJ \& Schmittgen TD 2001 Analysis of relative gene expression data using real-time quantitative PCR and the $2^{-(\Delta \Delta C t)}$ method. Methods 25 402-408. (doi:10.1006/meth.2001.1262)

Minhas BS, Zhu Y-P, Kim H-N, Burwinkel TH, Ripps BA \& Buster JE 1993 Embryonic platelet activating factor production in the rabbit increases during the preimplantation phase. Journal of Assisted Reproduction and Genetics 10 366-370. (doi:10.1007/BF01213432)

Nakatsuka M, Yoshida N \& Kudo T 1992 Platelet activating factor in culture media as an indicator of human embryonic development after in-vitro fertilization. Human Reproduction 7 1435-1439.

Nishi O, Tominaga T, Goto Y, Hayashi K \& Mori T 1995 Effects of platelet activating factor on mouse embryo implantation in vitro. Journal of Assisted Reproduction and Genetics 12 330-334. (doi:10.1007/ BF02213714)

Notredame C, Higgins DG \& Heringa J 2000 T-Coffee: a novel method for fast and accurate multiple sequence alignment. Journal of Molecular Biology 302 205-217. (doi:10.1006/jmbi.2000.4042)

O'Neill C 1985 Partial characterisation of the embryo-derived plateletactivating factor in mice. Journal of Reproduction and Fertility $\mathbf{7 5}$ 375-380. (doi:10.1530/jrf.0.0750375)

$\mathbf{O}^{\prime}$ Neill C 1997 Evidence for the requirement of autocrine growth factors for development of mouse preimplantation embryos in vitro. Biology of Reproduction 56 229-237. (doi:10.1095/biolreprod56.1.229)

$\mathbf{O}^{\prime}$ Neill C 1998 Autocrine mediators are required to act on the embryo by the 2-cell stage to promote normal development and survival of mouse preimplantation embryos in vitro. Biology of Reproduction $\mathbf{5 8}$ 1303-1309. (doi:10.1095/biolreprod58.5.1303)

O'Neill C 2005 The role of Paf in embryo physiology. Human Reproduction Update 11 215-228. (doi:10.1093/humupd/dmi003)

Pearson WR \& Lipman DJ 1988 Improved tools for biological sequence comparison. PNAS 85 2444-2448. (doi:10.1073/pnas.85.8.2444)

Poole WE, Simms NG, Wood JT \& Lubulwa M 1991 Tables for age determination of the Kangaroo Island wallaby (tammar), Macropus eugenii, from body measurements. Lyneham, A.C.T: CSIRO, Division of Wildlife and Ecology. Technical memorandum no. 32.

Prescott SM, Zimmerman GA, Stafforini DM \& McIntyre TM 2000 Platelet-activating factor and related lipid mediators. Annual Review of Biochemistry 69 419-445. (doi:10.1146/annurev.biochem.69.1.419)

R Development Core Team 2010 R: a language and environment for statistical computing. R Foundation for Statistical Computing. v 2.11.1.

Renfree MB 1972 Influence of the embryo on the marsupial uterus. Nature 240 475-477. (doi:10.1038/240475a0)

Renfree MB 1994 Endocrinology of pregnancy, parturition and lactation in marsupials. In Pregnancy and Lactation, Part 2. Fetal Physiology Parturition and Lactation, Marshall's Physiology of Reproduction, pp 677-766. Ed. G E Lamming. London: Chapman \& Hall.

Renfree MB \& Calaby JH 1981 Background to delayed implantation and embryonic diapause. In Embryonic diapause in mammals: proceedings of a symposium held at Thredbo, New South Wales, Australia, February, 1980. Journal of Reproduction and Fertility. Supplement 29 1-9.

Renfree MB \& Shaw G 2000 Diapause. Annual Review of Physiology 62 353-375. (doi:10.1146/annurev.physiol.62.1.353)

Renfree MB \& Tyndale-Biscoe CH 1973 Intrauterine development after diapause in the marsupial, Macropus eugenii. Developmental Biology 32 28-40. (doi:10.1016/0012-1606(73)90217-0)

Renfree MB \& Tyndale-Biscoe CH 1978. Manipulation of marsupial embryos and pouch young. In Methods in Mammalian Reproduction, pp 307-331. Ed: JC Daniel Jr. New York: Academic Press, Inc.

Renfree MB, Green SW \& Young IR 1979 Growth of the corpus luteum and its progesterone content during pregnancy in the tammar wallaby, Macropus eugenii. Journal of Reproduction and Fertility 57 131-136. (doi:10.1530/jrf.0.0570131) 
Roudebush WE, Duralia DR \& Butler WJ 1996 Effect of platelet-activating factor (PAF) on preimplantation mouse $\mathrm{B}_{6} \mathrm{D}_{2} \mathrm{~F}_{1} / \mathrm{J}$ embryo formation. American Journal of Reproductive Immunology 35 272-276. (doi:10. 1111/j.1600-0897.1996.tb00044.x)

Roudebush WE, LaMarche MD, Levine AS, Jiang H \& Butler WJ 1997 Evidence for the presence of the platelet-activating factor receptor in the CFW mouse preimplantation two-cell stage embryo. Biology of Reproduction 57 575-579. (doi:10.1095/biolreprod57.3.575)

Roudebush WE, Purnell ET, Stoddart NR \& Fleming SD 2002 Embryonic platelet-activating factor: temporal expression of the ligand and receptor. Journal of Assisted Reproduction and Genetics 19 72-78. (doi:10.1023/ A:1014443630722)

Roudebush WE, Massey JB, Kort HI, Elsner CW, Toledo AA \& Shapiro DB 2003 Expression and presence of the platelet-activating factor receptor in human embryos. Fertility and Sterility 79 1246-1248. (doi:10.1016/ S0015-0282(03)00073-6)

Ryan JP, Spinks NR, O'Neill C, Ammit AJ \& Wales RG 1989 Platelet activating factor (PAF) production by mouse embryos in vitro and its effect on embryonic metabolism. Journal of Cellular Biochemistry 40 387-395. (doi:10.1002/jcb.240400314)

Ryan JP, O'Neill C \& Wales RG 1990a Oxidative metabolism of energy substrates by preimplantation mouse embryos in the presence of plateletactivating factor. Journal of Reproduction and Fertility 89 301-307. (doi:10.1530/jrf.0.0890301)

Ryan JP, Spinks NR, O'Neill C \& Wales RG $1990 \mathrm{~b}$ Implantation potential and fetal viability of mouse embryos cultured in media supplemented with platelet-activating factor. Journal of Reproduction and Fertility 89 309-315. (doi:10.1530/jrf.0.0890309)

Sharkey AM, Dellow K, Blayney M, Macnamee M, Charnock-Jones S \& Smith SK 1995 Stage-specific expression of cytokine and receptor messenger ribonucleic acids in human preimplantation embryos. Biology of Reproduction 53 955-962. (doi:10.1095/biolreprod53.4.974)

Shaw G 1996 The uterine environment in early pregnancy in the tammar wallaby. Reproduction, Fertility, and Development 8 811-818. (doi:10.1071/RD9960811)

Shaw G \& Renfree MB 1984 Concentrations of oestradiol-17 $\beta$ in plasma and corpora lutea throughout pregnancy in the tammar, Macropus eugenii. Journal of Reproduction and Fertility 72 29-37. (doi:10.1530/jrf.0.0720029)

Shaw G \& Renfree MB 1986 Uterine and embryonic metabolism after diapause in the tammar wallaby, Macropus eugenii. Journal of Reproduction and Fertility 76 339-347. (doi:10.1530/jrf.0.0760339)

Spindler RE, Renfree MB, Shaw G \& Gardner DK 1998 Reactivating tammar wallaby blastocysts oxidise glucose. Biology of Reproduction $\mathbf{5 8}$ 1425-1431. (doi:10.1095/biolreprod58.6.1425)

Spindler RE, Renfree MB, Shaw G \& Gardner DK 1999 Reactivating tammar wallaby blastocysts oxidize fatty acids and amino acids. Journal of Reproduction and Fertility 115 79-86. (doi:10.1530/jrf.0.1150079)
Stoddart NR, Wild AE \& Fleming TP 1996 Stimulation of development in vitro by platelet-activating factor receptor ligands released by mouse preimplantation embryos. Journal of Reproduction and Fertility 108 47-53. (doi:10.1530/jrf.0.1080047)

Stojanov T \& O'Neill C 1999 Ontogeny of expression of a receptor for platelet-activating factor in mouse preimplantation embryos and the effects of fertilization and culture in vitro on its expression. Biology of Reproduction 60 674-692. (doi:10.1095/biolreprod60. 3.674)

Thornber EJ, Renfree MB \& Wallace GI 1981 Biochemical studies of intrauterine components of the tammar wallaby Macropus eugenii during pregnancy. Journal of Embryology and Experimental Morphology 62 325-338.

Tiemann U 2008 The role of platelet-activating factor in the mammalian female reproductive tract. Reproduction in Domestic Animals 43 647-655. (doi:10.1111/j.1439-0531.2007.00959.x)

Tiemann U, Bücher K, Pfarrer C, Pöhland R, Becker F, Kanitz W \& Schmidt P 2005 Influence of ovarian steroid hormones or plateletactivating factor on mRNA of platelet-activating factor receptor in endometrial explant perfusion cultures from ovariectomised bovine. Prostaglandins \& Other Lipid Mediators 76 35-47. (doi:10.1016/ j.prostaglandins.2004.10.006)

Tommaso PD, Moretti S, Xenarios I, Orobitg M, Montanyola A, Chang J-M, Taly J-F \& Notredame C 2011 T-Coffee: a web server for the multiple sequence alignment of protein and RNA sequences using structural information and homology extension. Nucleic Acids Research 39 W13-W17. (doi:10.1093/nar/gkr245)

Tyndale-Biscoe CH 1978 Hormonal control of embryonic diapause and reactivation in the tammar wallaby. In Symposium on Maternal Recognition of Pregnancy, pp 173-190. London: Ciba Foundation.

Tyndale-Biscoe CH \& Renfree MB 1987 In Reproductive Physiology of Marsupials. Cambridge: Cambridge University.

Tyndale-Biscoe CH, Hearn JP \& Renfree MB 1974 Control of reproduction in macropodid marsupials. Journal of Endocrinology 63 589-614. (doi:10.1677/joe.0.0630589)

Velasquez LA, Aguilera JG \& Croxatto HB 1995 Possible role of plateletactivating factor in embryonic signaling during oviductal transport in the hamster. Biology of Reproduction 52 1302. (doi:10.1095/biolreprod52. 6.1302)

Received 6 April 2013

First decision 2 May 2013

Revised manuscript received 20 September 2013

Accepted 8 October 2013 